\title{
PROPERTIES, CONTROL AND ICR-HEATING OF THE PLASMA IN TEXTOR
}

G.H. Wolf, H.L. Bay, G. Bertschinger, W. Biegerl, P. Bogen, W. Brüssau, G.A. Campbe112, Y. Cao ${ }^{3}$, R.H. Conn 2 , K.H. Dippel, H.G. Esser, K.H. Finken, G. Fuchs, B. Giesen, D.M. Goebe ${ }^{2}$, E. Graffmann, H. Hartwig, E. Hintz, F. Hoenen, K. Höthker, A. Kaleck, H. Kever, L. Könen, M. Korten, L. Li3, Y.T. Lie, W.K. Leung ${ }^{2}$, A.E. Pontau4, A. Pospieszczyk, D. Reiter, A. Rogister, G. Ross ${ }^{5}$, D. Rusbuldt, L. Sam, B. Schweer, J. Schlüter, H. Soltwisch, W. Stodiek 6 , G. Thomas $4, F$. Waelbroeck, G. Waidmann, P. Wieniold, J. Winter, R. Yamauchi

Institut für Plasmaphysik, Kernforschungsanlage Jülich GmbH, Association EURATOK-KFA, D-5170 Jülich, FRG

Fachochschule Jülich, D-5170 Jülich, FRG. 2triversity of Caifformia at Los Angeles, USA. 3istitute of Plasma Physics, Acaderia Sinica, Hefei, The People's Republic of China. "Sandia National Laboratories, Livernore, USA. 5-NRS-ENERGIE, Varennes, Quebec, Canada. GPrinceton Plasma Physics Laboratory, USA. TJAERI, Tokai, Japan

$$
\text { and }
$$

T. Delvigne, P. Descamps, F. Durodié, M. Jadoul, R. Koch, D. Lebeau, A.Y. Messiaent, D.I.C. Pearson, P.E. Vandenplas, R. Van Mieuventrove, G. Van Oost, G. Van hassenhove, R.R. Heynants"

Plasma Physics Laboratory, Ecole Militaire/Koniki jke Militaire School, Association EiRATOM-Belgian State, B-10:0 3russeis

+Senior research associate at the NFSR, Beigium

\section{ABSTRACI}

The accessible parameter range, the impurtty contents and the suscept:b: it: $: 0$ :CR: powe:

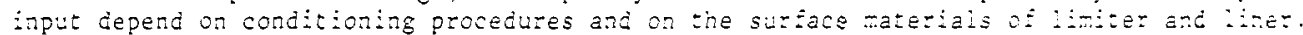
The respective combinations stainless steel and incone:, "carbonizet" stainiess stee: and "carbonized" incone! as well as "carbonized" grapiite and "carbonized" Sncone: have bee compared. For the latter pulses of up to 3.8 sec duration and loop voltages be:cri 1000.2

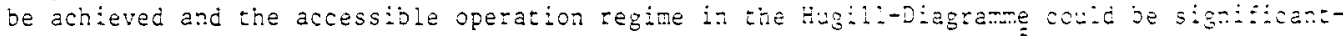
$1 y$ extended. The metal concentrations were reduced to the order of $10^{-5}$, itereas the tote: concentration of carbon and oxygen impurities was typicaliy azound two to three percent.

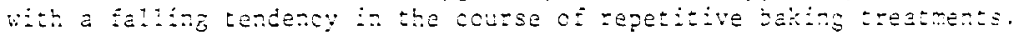

Results on $j(r)$ derived from polarinetry are presented and discussed in act ases ihe

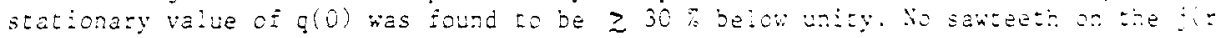
protile could be observed.

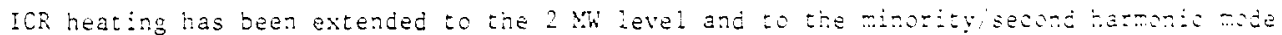

The $\tau_{\text {E-scaling still remains comparable to that of the L-regime. }}$ ith the tirsaz

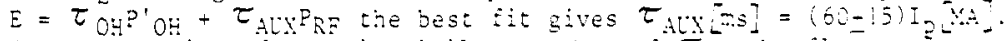

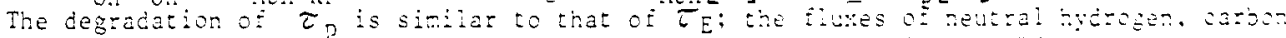
and oxygen and the value of $n_{e}$ close to the $:$ miter ancease with the st power. Pronounce

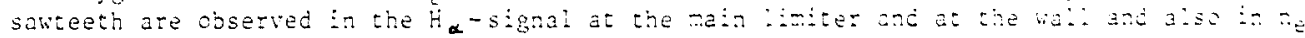
close to the limiter lith ampitudes ot up to 50 i.

The application of ICRH increases the particle remova: by the pump :initer dit-1 as a an-

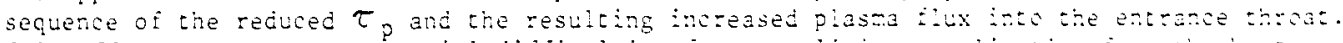

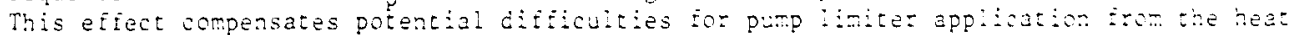

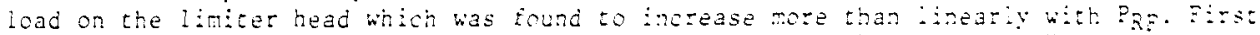
experiments uth localized pertubbation coils for boundary "ezgotization" resulted $\vdots 2$ a pasnounced stationary island pattern in the boundary layez they sniluence the gicbal plasma confinement and, in some cases, led to a quench of the incernal m=? moce. 
The TEXTOR research programe / // focusses on the systematic analysis of plasma wall interaction, the development of a suitable wall system and the production of quasi-stationary long-pulse high-temperature plasmas with tolerable impurity concentrations, with well-defined boundary layer and with relevant particle and power fluxes through the boundary.

First, the present paper describes the method of wall carbonization developed in Jülich /2-5/ and some characteristic features of the TEXTOR plasma /6/ obtained with this method for both, tetal 1 imiters and graphite Iimiters. Moreover, the effect of ICRH heating $(2 \mathrm{MW}, ! \mathrm{sec}) / 7,8 /$ on plasma parameters and on the boundary layer $/ 9,10 /$ is discussed, together with the application of the single head pump liniter ALT-I /11-13/ and of the localized set of magnetic perturbation coils for boundary "ergodization" /14-16/.

Originally, TEXTOR had been operated with an inconel liner and with a system of stainiess steel limiters $/ 17 /$. Under these conditions, the plasma discharges were characterized by concentrations of metallic impurities - depending on $\mathrm{n}_{e}$ - of up to several $10^{-4}$ and of a disruption limited tolerable ICRH power limit of only 100 to $200 \mathrm{~kW} / 18 /$. The plasma-chemical deposition of carbon on the first vall has been developed for TEXTOR in order to suppress the production of metallic impurities and to achieve a satisfactory susceptibility of the plasma to poverful long-pulse ICRH heating. It may be recalled that until recently the method of impurity control - in limiter Tokamaks - generally consisted of the use of (i) graphite limiters (and protection plates), (ii) metal walls and (iii) Ti- or Cr-gettering in particular in order to reduce the oxygen concentration. This procedure had the disadvantage that in the course of Tokamak operation the graphite limiters became increasingly contaminated by the redeposition of metallic vall material which also led to a steady increase of the metal impurity concentration in the plasma core.

Carbonization suppresses this mechanism. Carbonization is the plasma-chemical coating of the whole vall system with a sufficiently thick (i.e. several hundzed monolayers) amorphous carbon layer of a relative hydrogen (deuterium) content of about 0.4 .

This layer can be applied by a specific radio-frequency assisted glow discharge in an acjustable mixture of e.g. $D_{2} / C D_{4}$. Any desired ratio between the $H$ and $D$ composition of the plasma can be obtained. The method is well-defined and reproducible. By means of appropriate glowdischarge cleaning the coating can also be completely removed.

First, carbonization has been applied upon the above nentioned all metal wall systeth. The success of this method led to a reduction of the metal concentration in the plasma core towards the $10^{-5}$ regime and to the possibility of coupling ICRH power (with the same antenna system) in the MW-regime. Erosion of the carbonization layer on the exposed parts of the limiters, hovever, led to the need for some recarbonization after about 100 discharges. Moreover, stainless steel as the bulk material of the limiters is not considered suitabie to accept high power fluxes, e.g. on the leading edges.

Therefore, the material of the limiter system, i.e. Of the movable main limiters, of the antenna protection limiters and of the inboard limiter (aainly for protection against diszuptions), has been changed over from stainiess steel to graphite during the last summer break. Initialiy, this led to a pronounced prolongation of the operational period until recarbonization is required. However, as compared to the carbonized metal system, there is now an even more apparent source-sink behaviour of the limiter system with respect to the hydrogen balance, and the $C$ and/or $O$ concentration is roughly twice that as obtained before: the latter depends strongly on the application of intense baking after which a significant reduction of the $C$ and/or $O$ content can be achieved. A comparison between these cases is given

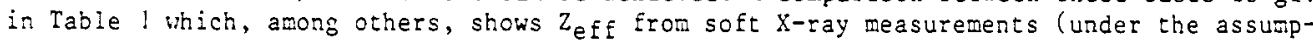
tion of equal $C$ and $O$ concentration). Since in the course of TEXTOR operation some metal erosion has occurred e.g. from diagnostic probes, we observed also some metallic contamination of the graphite limiters: this led to recarbonization requirenents which are comparable to the situation with carbonized metal limiters.

From a systematic study of parametric dependences, a further comparison is comprised by the "Hugill-Diagramme" for these three cases which essentially shows that both, the q-limit and the density limit could be significantly shifted after carbonization had been applied: this holds for both limiter materials, stainless steel and graphite. The present density limit with OH-discharges at $2.0 \mathrm{~T}$ Iies at $\overline{\mathrm{n}}_{e}=5.3 \times 10^{13} \mathrm{~cm}^{-3}$ (with ICRH it could be shifted to 


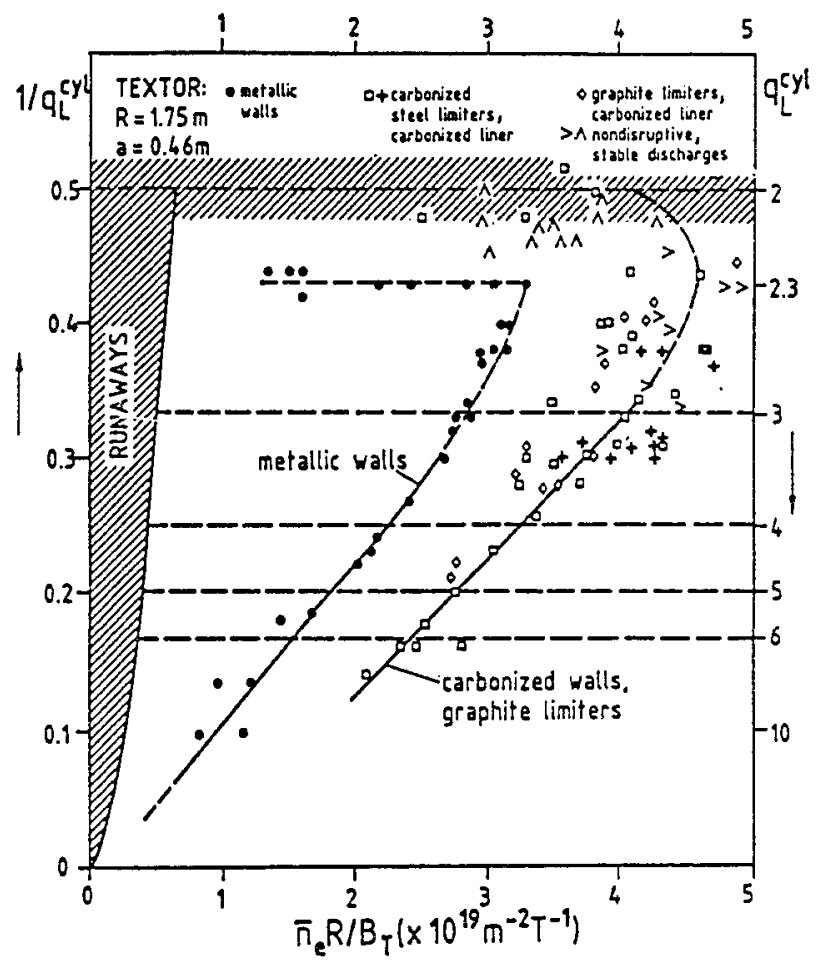

Fig. 1. Operational regine of OHdischarges for metallic limiters and walls $\bullet$, for cerbonized metaliic limiters and walls a+, and for carbonized graphite iimiters ard (metalitic) walis $\Delta>$ $\left(B_{I} \leq 2.0 I, I_{D} \leq 5.0 \mathrm{kA}\right)$.

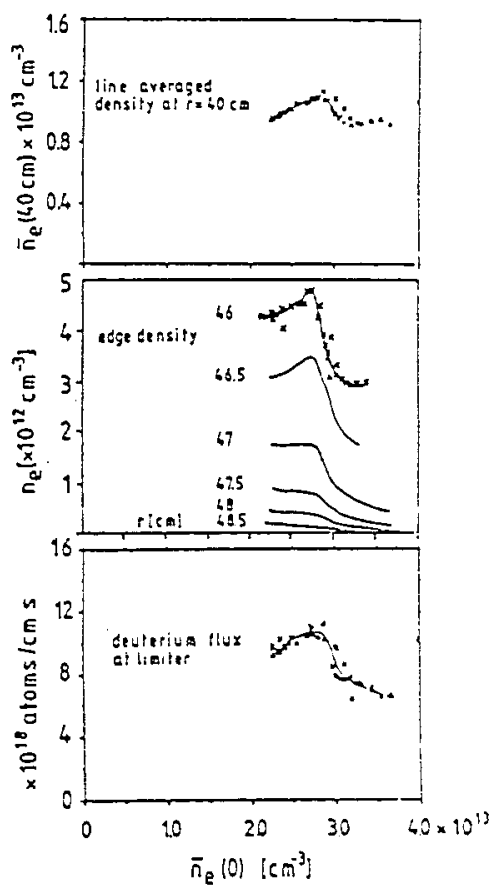

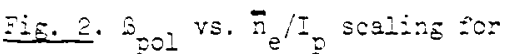
carbonized graphite liziters ard (metallic) wails.

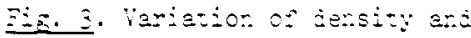

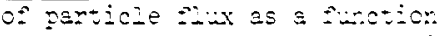
o: certrai Zine aversae Lersity $\bar{y}$ :or or jischarges ari :or

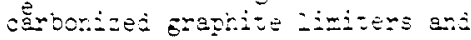
imezajic) weìs. 
$5.7 \times 10^{13} \mathrm{~cm}^{-3}$ ). The corresponding Murakami parameter which has now been achieved under OHconditions is

$$
M=\bar{n}_{e} \frac{R_{0}}{B_{T}}=4.9 \times 10^{19}\left[\mathrm{~T}^{-1} \mathrm{~m}^{-2}\right] .
$$

The above mentioned parameter scans permitted to establish - for $\overline{\mathrm{n}}_{\mathrm{e}}$ between $1 \times 1013$ and $5 \times 10^{13} \mathrm{~cm}^{-3}$ and for $I_{p}$ between $340 \mathrm{kA}$ and $500 \mathrm{kA}-$ a scaling of $\beta_{\text {pol }}$ :

$$
\beta_{p o l}=4.8 \times 10^{-9} \bar{n}_{e} / I_{p} \quad \text { with } \quad I_{p}[A], n_{e}\left[\mathrm{~cm}^{-3}\right] \text {, }
$$

which is shown in Fig. 2. The overall pulse duration of the discharges in this density range could be extended to $3.8 \mathrm{sec}$; for $B_{T}=2.0 \mathrm{~T}$ the value of $I_{p}$ could be increased to $540 \mathrm{kA}$ and $\tau_{E}$ reached $100 \mathrm{~ms}$. Upgrading of the TEXTOR nachine permits now to extend $B_{T}$ up to $2.6 \mathrm{~T}$ or even sightly beyond.

At higher densities, a broadening of the boundary layer, accompanied by increased luminosity, could be visually observed by use of a (tangentially viewing) TV-camera. Detailed measurements in the boundary have shown that, for $\bar{n}_{e} \geqslant 3 \times 10^{13} \mathrm{~cm}^{-3}$, the plasma starts to become detached from the limiter resulting in reduced fluxes, density and heat loads there $/ 10 /$ as can be seen in Fig. 3 .

\begin{tabular}{|l|c|r|c|}
\hline & \multicolumn{1}{|c|}{ without } & \multicolumn{2}{|c|}{ with carbonization } \\
\cline { 2 - 4 } & $\begin{array}{c}\text { inconel liner } \\
\text { steel liniters } \\
\text { a) }\end{array}$ & $\begin{array}{c}\text { inconel liner } \\
\text { steel liniters } \\
\text { b) }\end{array}$ & $\begin{array}{c}\text { inconel liner } \\
\text { graphite limiters } \\
\text { c) }\end{array}$ \\
\hline$Z_{\text {eff }}(0)$ & 3.2 & $1.6(1.2)$ & 2.0 \\
\hline $\bar{n}_{e}$ & $4.2 \times 10^{13} \mathrm{~cm}^{-3}$ & $4.6 \times 10^{13} \mathrm{~cm}^{-3}$ & $5.3 \times 10^{13} \mathrm{~cm}^{-3}$ \\
\hline Oxygen & $3 \times 10^{-2}$ & $6 \times 10^{-3}\left(2 \times 10^{-3}\right)$ & $1 \times 10^{-2}$ \\
\hline Carbon & $5 \times 10^{-4}$ & $6 \times 10^{-3}\left(2 \times 10^{-3}\right)$ & $1 \times 10^{-2}$ \\
\hline Iron & & $2 \times 10^{-5}\left(\leq 10^{-5}\right)$ & $2 \times 10^{-5}$ \\
\hline
\end{tabular}

TABLE ?. Typical composition of a ceuterium plasma for various wall conditions. Best values ever achieved for b) in brackets.

Impurity figures are relative concentrations on the axis. The carbon and oxygen values in $b$ ) and $c$ ) are evaluated under the assumption of equal concentration.

\section{CURRENT DENSITY PROEILES}

The poloidal magnetic field distribution in TEXTOR has been determined by probing the plasma with an array of HCX laser beams measuring the Faraday rotation of their planes of polarization and the phase shifts caused by the electron density /19/. The data analysis is based on the assumption of eccentric circular flux surfaces in accordance with numerical equilibrium calculations. The total error of the resulting current density profile is estimated to be about $+5 \%$ to $+10 \%$ at half the plasma radius. For the central current density an accuracy of $\pm 15 \%$ to $+2 \overline{0} \%$ is achieved by slowly moving the plasma across the probe beams and thereby virtually multiplying the number of chords $/ 20 /$. The agreement between the positions of the $q=1$ surface as determined by the Faraday rotation measurements and by temperature and density sawteeth confirms the absence of systematic errors. Temporal evolutions of the current density profiles have been determined for discharges with various magnitude and time dependen- 


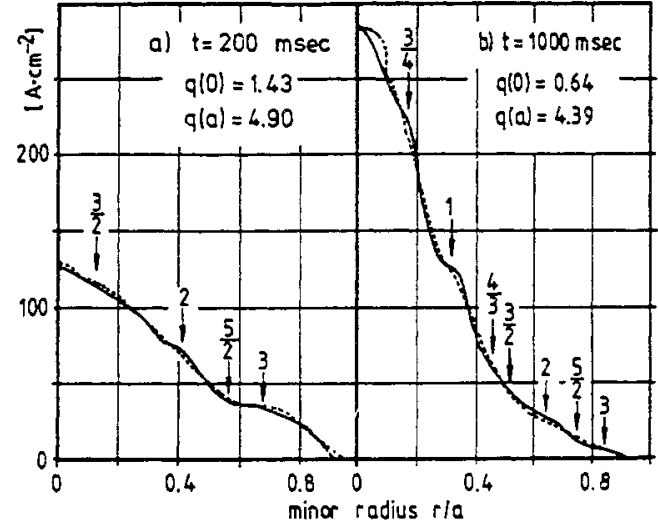

Fig. 4. Time development of the $j$ profize for the times of a) 200 end b) 1000 esec. a (0) develops from 1.4 to 0.64 . The dashed line gives tie measured values, whereas the solid ine represents computed stable profiles (except for $m=1$ ).

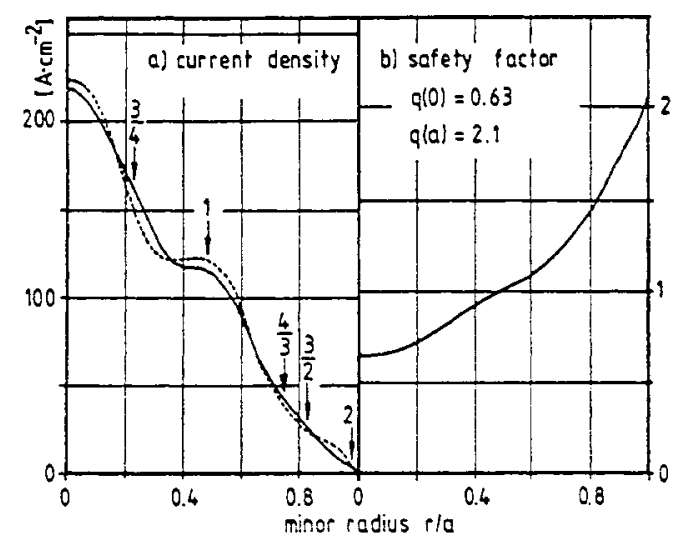

Fig. 6. a) Current density and $b)$ q protize with large $q=1$ surface of a aischarge which is first stable and then violent develops a $m=1$ mode ser. in $5 \dot{i}$. $?$.

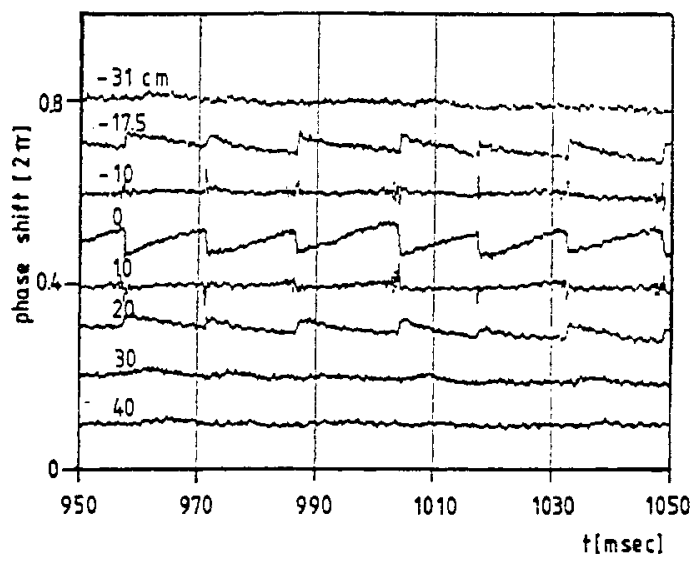

Fig. 5. Seitocti reiexazicrs o: Zine inzeGrated eiection dersizies for the case of Eig. L. The rumbers give the grsitiors of the prove bears relative to $I_{0}=175 \mathrm{~cm}$.

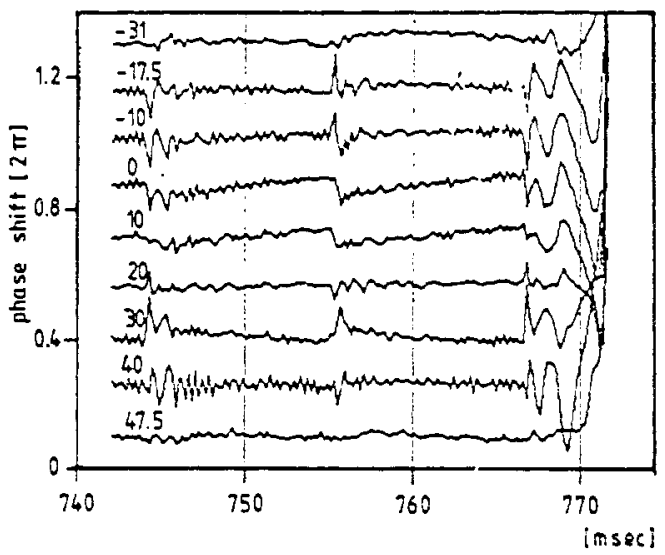

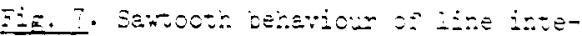

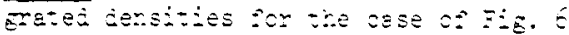

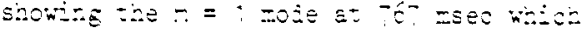
jeass to a zerminazion of the ijsorenge. 
ces of plasma current and toroidal field, and these have been compared with linear tearing mode stability theory using a cylindrical delta prime programe (kindly provided by K. Lackner, Garching).

In all cases marginally stable profiles could be generated for all modes with m=l which coincide with the measured profiles within the experimental accuracy. The m=l case is predicted unstable for all conditions with $g$ on axis less than l. It is thus surprising to observe that (as seen in Fig. 4) the current distribution develops in time with $q(0)$ going from 1.4 at $200 \mathrm{msec}$ down to 0.64 at $1000 \mathrm{msec}$ without leading (necessarily) to a large m=1 internal kink instability, which would depress the current density profile by reconnection to $q(0)=1$. Sawtooth activity is nevertheles observed in such cases (Fig. 5) flattening the temperature and density profiles, but apparently not the current density profile.

For this situation we conclude that the sawtooth activity, especially under the persistent condition of $q(0)$ significantly less than 1 , cannot be the result of a complete reconnection process involving the $\mathrm{m}=\mathrm{l}$ internal kink mode, because of the impossibility of recovery of low $q$ on axis between sawtooth relaxations $/ 21 /$.

However, the generally predicted rapid growth of the $\mathrm{m}=1$ internal kink for the case of $q(0)$ about 0.6 has also been observed (Fig. 6). After more than $0.5 \mathrm{sec}$ during which the current distribution has shown a fairly stationary behaviour with only small density sawteeth (Fig.7), a large $\mathrm{m}=$ ? mode develops, and the observed negative voltage spike indicates a large poioidal flux change. Eventually, this leads to a termination of the discharge. These phenomena would be dificult to understand with the assumption of $q(0)$ near 1 .

Conditions under which the resistive $m=1$ mode may be marginally stable are not known theoretically for $q$ on axis significantly less than 1 and are now being investigated /22/.

\section{ION CYCLOTRON HEATING AND RESULTING EFFECTS}

\section{Introduction}

The principal features of the previous ICRH results on TEXTOR have been reported in $/ 23 /$ and /7/. The most important changes for the conditions of the ICRH operation reported here are: 1) the use of main and antenna Iimiters made of graphite to replace the previous stainiess steel ones; 2) the use of identical top and bottom antennae /24/ with central conductors of the broad type (mean width: $17 \mathrm{~cm}$ ); 3) the use of low minority concentrations in a $D-(H)$ plasma $\left(N_{H} / N_{D}<1 \%\right)$, instead of the previous mode conversion regime.

With these changes the general characteristics of the results remain the same as those reported in $17 /$. Long pulse $(\sim$ is), low impurity ICRH with stationary plasma parameters has been obtained but now with an RF power fed to the antenna $P_{A}$ which has reached 2.3 MW. Given an antenna loss of $180 \mathrm{kH}$, about $92 \%$ of this value contributes to $\mathrm{P}_{\mathrm{RF}}$, the power effectively radiated into the machine, yielding a total power coupled to the plasma $P_{\text {tot }}=P_{R F}+P_{O H}^{\prime}$ of $2.5 \mathrm{MW}$, which is 6.3 times the remaining OH power P'OH at a plasma current $\mathrm{I}_{\mathrm{p}}=500 \mathrm{kA}$, which causes also a lengthening of the current flat-top by dieans of the resulting Vs saving. An adequate wall carbonization is also mandatory to bring up the power at the Mw level without plasma disruption or antenna breakdown. This consists of glow discharge in a mixture of $D_{2}$ and $\mathrm{CD}_{4}$, in order to reach the low $\mathrm{H}$ isotopic content in the tokanak discharge, and is followed by a baking of the C-Iimiters to avoid a large gas release during ICRH. The results reported here correspond to $I_{p}=0.48-0.50 \mathrm{MA}, B_{0}=1.9-2.0 \mathrm{I}$ and a main limiter radius of $0.46 \mathrm{~m}$.

Results pertaining to a typical $2 \mathrm{MW}$ shot are shown in Fig. 8: a) Temporal evolution of the total plasma energy content. E dia is measured by diamagnetism and $E_{\text {egu }}$ (dotted line curve) is computed from an equilibrium code using the measured vertical fielguand the current density profile as input data. The kinetic energy content $E_{\text {, as }}$ computed from the electron density and temperature profiles, the central ion temperature $T$, and assuming the same ion temperature profile as for the electrons leads to a value $\sim 28$ ' $\%$ lower. b) Temporal benaviour of the cotal number of electrons $N$ in the discharge as obtained from HCN interferometry. () The central electron energy density ${ }^{e} E_{e o}=3 / 2 n_{e o} T_{e o}$ computed from the ECE signal from $\mathrm{T}$ eo and the Abel inverted HCN data for the central density $\mathrm{n}_{e 0^{\circ}}$ d) The central ion temperature $\mathrm{T}_{\text {io }}$, 
in a solid line, as obtained from the neutron yield. The dotted line shows for comparison $\mathrm{T}_{\text {io, }} \mathrm{A}$ as computed from equipartition alone (Artsimovitch law) using $\mathrm{n}$ and $I_{\text {eo }}$ as input data. The larger value of $T_{i}$, neutron with respect to the equipartition value in the ICRH part of the shot is attributed to direct RF heating of the ions. e) The current profile parameter $\alpha_{j} / 25 /$ obtained from the HCN polarimetric data using the following approximate relation for the current density profile $j=j o R_{0} / R\left[\left(1-r^{2} / a^{2}\right)^{\alpha j}-\mathcal{E}(r)\left(R-R_{0}\right) / R\right]$ with $|\mathcal{E}(r)|<0.5$.

A large broadening of the density profile occurs during ICRH (see Fig. 9c), whereas no change or, at most, a slight flattening of the j-profile is observed.

\section{Energy and GLobal Energy Confinement Time Scaling}

The energy increase appearing during ICRH is always partly due to an increase in density (as reflected by $N_{\text {en }} \mathrm{Fig}$. $8 \mathrm{~b}$ ) and changes in its profile. In order to decouple the effect of density increase from the effect of the total power coupled to the plasua $P$ on the energy content $E$ and resulting global energy confinement time $\tau_{E}=E / P$ tot, a coteful seiection of shots has been made with the same central chord density ne for vatious values of $P_{t o t}$ (power scan) or the same ${ }_{\text {for }}$ and various $n$ (density scan). To rinimize the scatter in the experimental points these have been chosen from the same series of shots. The results are shown in Fig. 9 a for the power scan and in Fig. 10 for the density scan. The conservative value of $E=E_{i j} / 1.2=E_{k i n}$ is taken. As for the mode conversion regime analysis $/ 2 /$, the results pertain tia an L-mode type scaling which is found in agreenten with either: ( Kaye-Goldston scaling $/ 26 /$ expressed as $E_{K-G}(\mathrm{~kJ})=0.02 \overrightarrow{\mathrm{n}}_{\mathrm{e}}^{0.26} \mathrm{P}_{\cot } 0.42_{\mathrm{p}} \mathrm{i}^{1.24}\left(10^{13} \mathrm{c=} \mathrm{s}^{-3}\right.$, $M W, k A)$ and valid for $P_{\text {tot }}>3 \mathrm{P}^{\prime}{ }_{\mathrm{OH}}$; this has a vanishing value ố $\tau_{E}$ for large $P_{\text {tot }}$, or: (ii) a less pessimistic scaling law using an asympotic, non-zeto auxiliary heating confinement

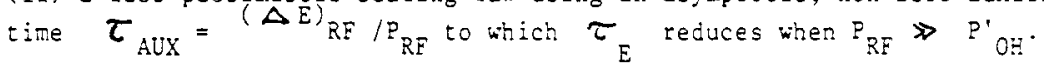

As in $\operatorname{Ref.} / 7 /$ we take

$$
E=\tau_{O A} P_{O H}^{\prime} \cdot \tau_{A U X} P_{R E}
$$

assuming that $\tau_{O H}$ is the $O H$ confinement time taken at the (constant) neo reached during RF and for the given machine parameters ( $B_{f}, I_{0}, R_{0}$, a). For the power range and the plasma parameters considered in Fig. 9 , a good fif' for the dependence of $P^{\prime}$ OH on $P_{R F}$ is given by $\mathrm{P}_{\mathrm{OH}}^{\prime}=\mathrm{P}_{\mathrm{OH}}-\delta \mathrm{P}_{\mathrm{RF}}$ with $\delta=0.1$. This value of $\delta$ is also roughly in agreezent with the expectation frow Spitzer resistivity and the observed nean I increase shown $\vdots$ Fig. 11 . Introducing $P^{\prime}$ in $E q(1)$ one obtains the linear law $E=A+B P$ show in Eig. Ga. The de-

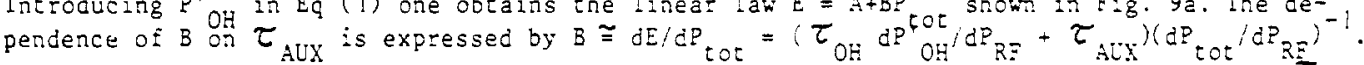
The corresponding nean value of $\tau_{\mathrm{AX}}=24$ as together with the values of $\tau_{\mathrm{ALX}}$ derived from $E_{q}$. (1) for each experimental point are aiso indicated in Fig. 93.

The results pertaining to the density scan are shown in Fig. 10. The OH curve (Ptot $=P_{0}$ i $=$ $0.6 \mathrm{MW}$ ) reflects the neo-Alcator behaviour of IEXTOR as expressed by Eq. (7) o: ReF. /7/. It appears that the increase of $\tau_{E}$ with $\bar{n}_{e}$ becomes less and iess pronounced as $p_{t o}$ increases

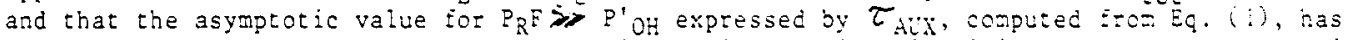
practically no longer a dependence on density. This behavicur is similaz to that observed with XBI in ASDEX /27/. We also note: (1) that the change of $\tau_{E}$ from the OH to the ICRH phase of a shot depends on the chord densities $\vec{B}_{e}$ achieved in OH and during ICRH; the arrows $\vdots$ Eig. io show typical trajectories during single shots starting from the of and ending at the ICRH representative point. The $\tau_{E}$ degradation observed during a shot is thus particularly sensitive to the $\bar{n}_{e}$-evolution; (i $\left.i\right) F i g .10$ suggests that no $\tau$ E degradation occurs at relatively low densities $\overrightarrow{\mathrm{a}}_{\mathrm{e}}=1.5 \times 10^{13} \mathrm{~cm}^{-3}$. The direct confirmation of such a behaviour was not possible due to the lack of sufficient control of the density :ise during high powet ICRti. As shown in Fig. 12 a and discussed below the particle continement titu $\tau_{p}$ undergces a similat degradation to that of $\tau_{E}$ as $P_{t o t}$ is increased.

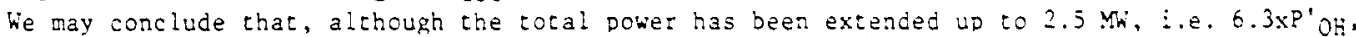
it is still not yet possible to rule out a kaye-Goldston $\tau_{E}$ scaling but, on the other hand, the results are consistent with a non vanishing $\tau_{\text {AUX }}$. Comparing the results of Ref. $/ 7 /$ with these, it appears that the value of $\tau_{E}$ obtained with low sinority concentration is similar or slightly lower than observed with mode conversion. All the results are compatible with the scaling law of $\mathrm{Eq}_{\mathrm{q}}$. (1) choosing $\tau_{\mathrm{AUX}}(\mathrm{ms})=\left(60_{ \pm} 15\right) \mathrm{I}_{\mathrm{p}}(\mathrm{MA})$. 


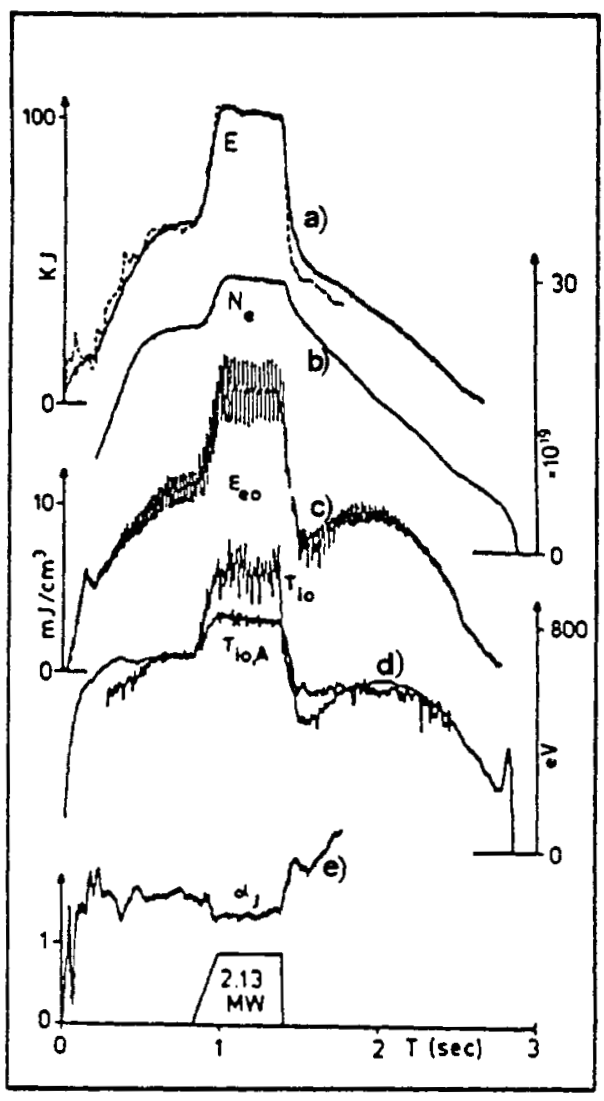

Fig. 6. Time evolution of various plasma parameters during an ICRH heated shot( $\$ 19161$ ). a) $E$ is the plasma energy content (solid line Edia, dotted line Eequ), b) $\mathrm{N}_{e}$; c) $E_{e o}=1.5 n_{e o} T_{e o}$ is the central electron energy density ; d) Central ion temperature (i) $T_{\text {io }}$ measured from neution emission (ii) Tio, computed from equipartition ; e) Current profile parameter $\alpha_{j}$.

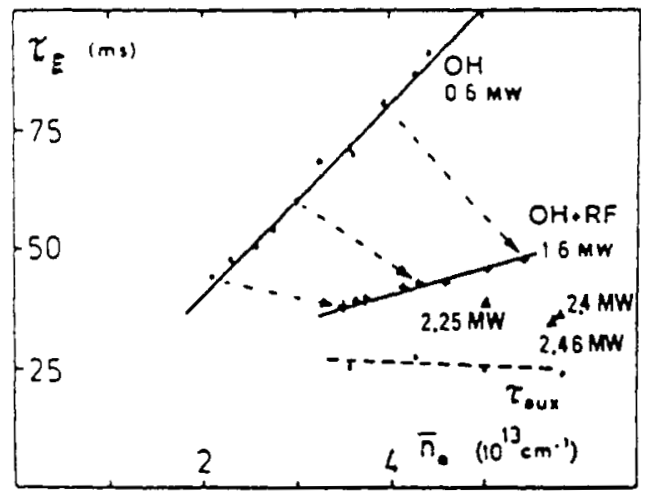

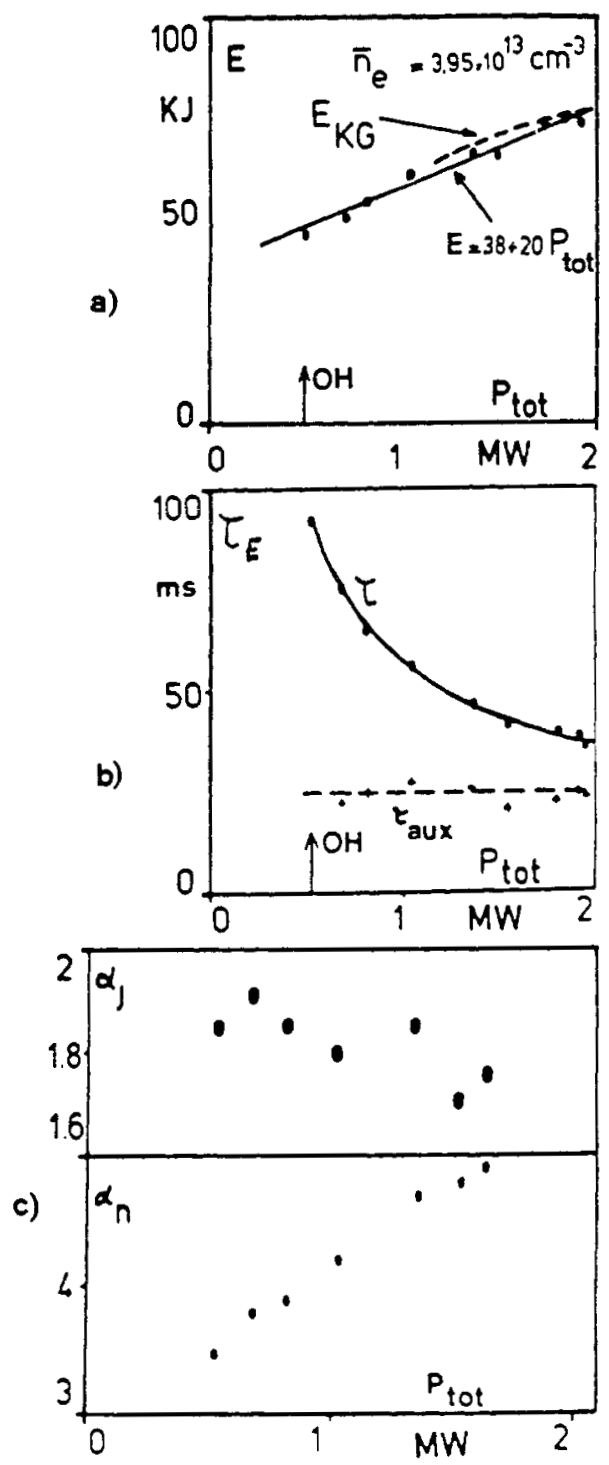

Fig. $\theta$. Power scan results (at constant $\bar{n}_{e}=$ $3.95 \times 10^{13} \mathrm{~cm}^{-3}$; shots $\left.\$ 19513-19537\right)$, a) Plasma energy content as compared with the Kaye-Coldston scaling (dotted 1 ine) and the scaling of Eq. (1) (solid line) ; b) Global confinement time $\tau_{E}$ with the corresponding values of TAUX calculated from Eq. (1);c) Corresponding variation of the current profile parameter $\alpha_{j}$ and the density profile parameter $a_{n}$.

Fig. 10. Density scan evolution of $t_{E}$ at constant values of $P_{\text {tot }}=0.6 \mathrm{MW}(\mathrm{OH}$ only), $P_{\text {tot }}=1.6 \mathrm{MN}, 22.4 \mathrm{MW}(\mathrm{OH}+$ ICRH $)$ and derived values of $\tau_{A U X}$. The arrows indicate the evolution from the $O H$ to the ICRH phases in particulat shots ( $\$ 18940-18947,19161$, 20349, 20351). 


\section{Heating Results and Profile Consistency}

The observed incteases in central temperatures $T_{e 0}$ (ECE) and $T_{\text {io }}$ (neutrons) during the power scan experiment of Eig. 9 are shown, versus $P_{R F}$, in Fig. 11 . To The value of $T_{\text {io }}$ due only to energy equipartition, as predicted from the above-mentioned Artsimovitch law, is also indicated. When comparing these results with the corresponding mode conversion case (see Fig. 6 of $\operatorname{Ref} . / 7 /)$, it is seen that there is less electron heating and more ion heating for the present low minority concentration cxperiments. A sumary of the comparison is given in Table 2. The central RF Dover densities coupled to the electrons $P R F, e$ and to the ions PRF, $i$, as obtained from the central power density balance (see $\$ 4.2$ of Ref./7/), has a similar increase of $p_{R F, i}$ with respect to $P_{R F, e}$ in the present experiments, as also shown in $T a b l e ~ 2$. From Fig. 11, it appears also that the electrons loose less power and the ions gain less by equipartition in this regime. The smaller relative increase of the central electron energy density $E_{\text {eo }}$ as compared to the total energy increase (compare OH and ICRH Dhases on Fig. 8a and c) is attributable partly to the fact that ions are, relatively speaking, heated more than electrons and partly to the broadening of the density profile.

As shown on Figs. $8 e$ and $9 c$ and already stated at lower $P_{R F}$ in Ref./7/ there exists only a slight tendency towards broadening of the current profile with RF powez even if the total Dower fed to the plasma changes by a factor 5. On the contrary, the density profile signiicanty broadens when $P_{\text {tot }}$ increases. This appears on Fig. $10 \mathrm{c}$ where the evolution of the density profile parameter $\alpha_{n}$ is shown versus $P_{\text {tot }}$. (The approximate density profile depends on $\alpha_{n}$ by the relation $N_{e}=N_{0}\left(1-(r / a)^{\alpha}\right)$.

\section{Particle Confinement Time, Impurities and Edge Parameters}

Fig. 12 shows, as a function of ? and at constant density $n$, the behaviour of the particle confinement time $\tau$, deuter lot flux, impurities brilliance and concentration, $z$ e and the edge $\mathrm{T}_{e}$ and $\mathrm{N}_{e}$ dering the power scan experiment of Fig. 9. The following observations and conclusions can be made: (i) during this power scan the total number of electrons $x_{e}$ increases from 2.45 to $2.62 \times 10^{20}$ particles due to profile broadening (see Figs. 9c and $12 \mathrm{~g}$ ), i.e. an increase of only $\sim 7 \%$. As the relative increase of the deuterium fluxes at limiter $\Gamma_{D, L}$, antenna $\Gamma_{D, A}(F i g .12 b)$ and at the wall $\Gamma_{D, k}$ is auch lazger, the particle confinement time $\tau_{\mathrm{p}}=\mathrm{N}_{\mathrm{e}} /\left(\Gamma_{\mathrm{D}, \mathrm{L}}+\Gamma_{D, A}+\Gamma_{D, h}\right)$ degrades in a similar jashion to $\tau_{E}$ when $P_{\text {tot }}$ is increased. This can be seen from Fig. 12 a where $\tau_{p, \text { or }}=75 \pm 35 \mathrm{~ms}$. The relative increases in $\Gamma_{\mathrm{D}, \mathrm{L}}, \Gamma_{\mathrm{D}, \mathrm{A}}$ and $\Gamma_{\mathrm{D}}$, all around the wachine are roughly the same. This increase in $D$ flux has been confirmed by a permeation probe zetiod /28/. The dynamic inze evolution at the RF switch-on or off of these fluxes is discussed in detail in Ref. $/ 9 /$. (ii) The oxygen flux increases less stzongly than that of deuterium with $p$ ot $/ 9 /$. This explaines the slight decrease in the oxygen concentration $C_{0}$ observed from soit $x-r a y s$ in Fig. 12d (assuming that the soft $\mathrm{X}$-ray enhancement is only due to oxyger). The relative increases in the brilliance of OVI and CV, normalized with respect to the edge chord density at $r=40$, are also slight and show rough'y the same behaviour for $C$ as for 0 . There is thus no low-z impurity problem in the high power ICRH discharges vitin carbonized walis and $c$ liziters. (iii) The metallic impurity benaviour, show in Fig. 12e, is sotewhat atypical in that the concentration $C_{\text {Met }}$ (sum of $C=+F e+N i$ averaged at $r=5$ and $15 \mathrm{~cm}$ ) increases nore and is also larger than in other runs or earlier experiments /7,23/ due to somewhat different wall conditions. The production rechanism of these imurities is discussed $i .2 / 9 /$. (iv) The value of $Z_{\text {eff }}$ as given by the soft $x$-ray signal remains roughly constant as a function oz $P_{\text {tot; }}$ this is attributable to the combined effect of the increase in Cye and cectease in $\mathrm{C}_{0}$ and $\mathrm{C}_{C}$. (v) The evolution of the mean chord density at $r=40 \mathrm{~cm}$ (HCA interferometer) and the density and electron temperature measured by langmuit probes at $r=52 \mathrm{~cm}$ in the scrape-off layer (SOL) are shom in Figs. 12g, 12h and 12i. The increases in $\mathrm{n}_{e}, 40$ and $\mathrm{n}_{\mathrm{e}}, 52$ are haracteristic of the observed density profile broadening. The electron cemperature in the SOL undergoes a mild increase during ICRA. Its possible intluence on the increase of the sheath potential and resulting rise in the flux of deuterium from the wall is discussed in $19 /$. 

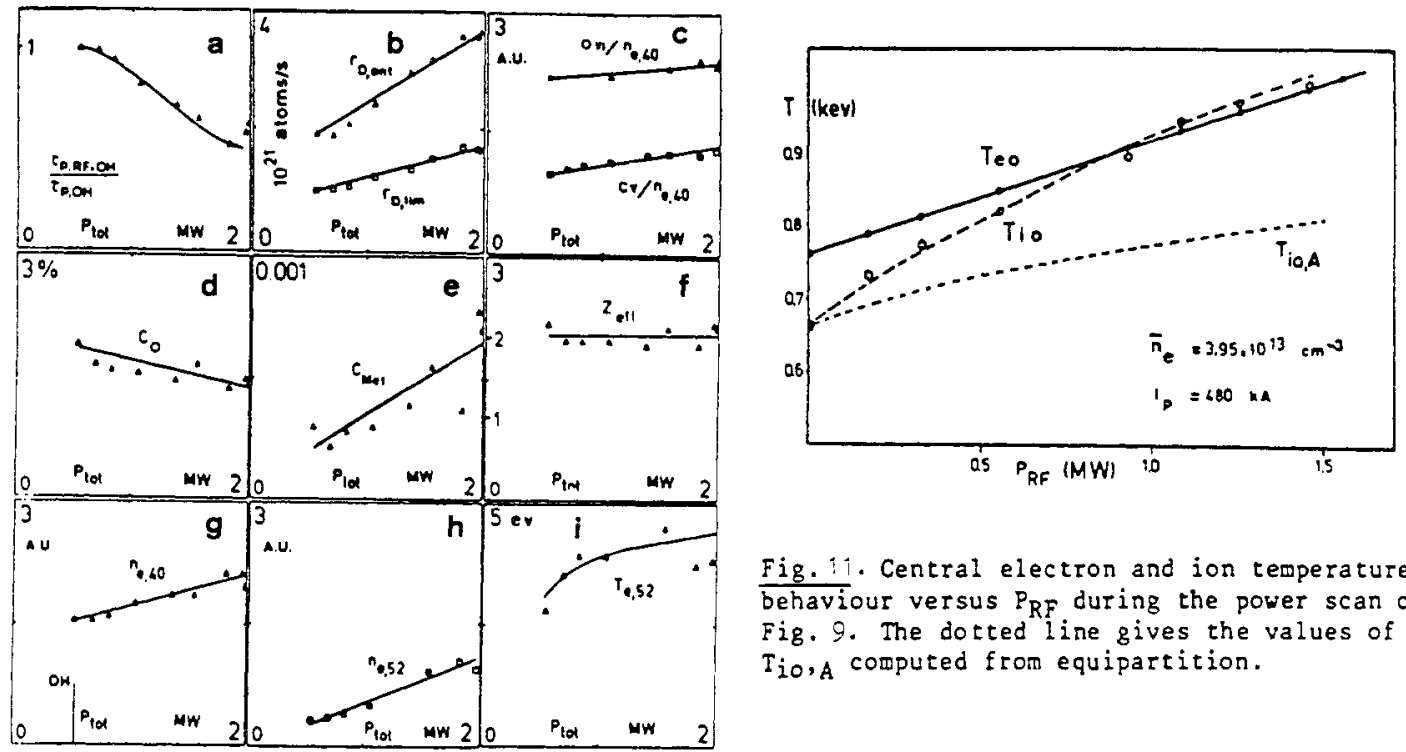

Fig. 11. Central electron and ion temperature behaviour versus $P_{R F}$ during the power scan of Fig. 9. The dotted line gives the values of $T_{\text {io, A }}$ computed from equipartition.

Fig. 12. Evolution of discharge parameters versus $P_{\text {tot }}$ for the power scan experiment at constant $\bar{n}_{e}$ value of Fig. $g$ : a) Particle confinewent time $\tau_{p}$; b) Deuterium flux from rain limiters and antenna limiters; c) Impurity line brilliance nomalized with respect to the edge chord density $\mathrm{n}_{\mathrm{e}} 40$ at $\mathrm{r}=40 \mathrm{~cm}$; d) Oxygen concentration from soft X ray data ; e) Metallic impurities concentration from soft $x$-rays; f) Corresponding $z_{e f f}$ value ; $g$ ) $n_{e, 40}$; h) and i) Langmuir probe measurement of $\mathrm{N}_{e}$ and $T_{e}$ at $r=52 \mathrm{~cm}$ in the $\mathrm{SOL}$.

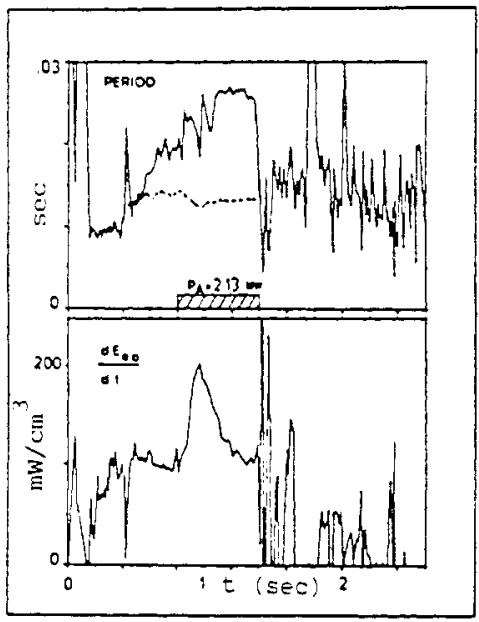

a)

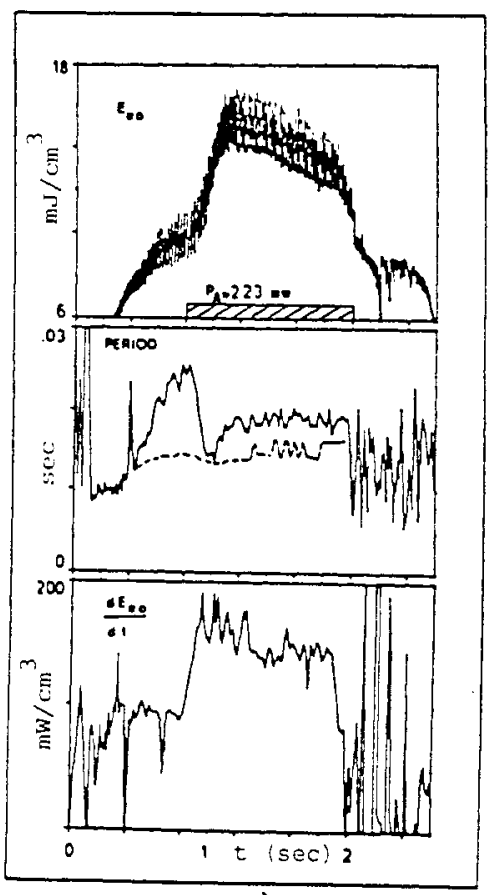

b)

Fig. 13. Evolution of the sawteeth period and electron energy slope dE eo/dt during 2 Mw ICRH heated shots : a) For the shot of Fig. $\delta$; b) For the shot $\$ 20351$; the corresponding curve of $E_{e o}$ is also given. The dotted line gives the results of the McGuireRobinson scaling for the period. 
Fig. 15 shows the response to a given ICRH pulse (of $1.3 \mathrm{MW}$ and $0.5 \mathrm{sec}$ ) of three different $n_{e}(r)$ signals, of the deuterium fluxes from limiter, antenna and liner and of the oxygen flux. These signals show as a particular feature the existence of pronounced sawteeth with amplitudes - for higher power levels - of up to $50 \%$. Signal b) of the lowest figure oresents the local density of iron atoms in front of a non-carbonized metallic target plate which is exposed to the plasma at a radial position of $=52.2 \mathrm{~cm}$, i.e. in a position which is more than $6 \mathrm{~cm}$ inside the limiter shadow. The increase of the sputtered iron density there by more than one order of magnitude suggests that sufficiently energetic ions are present in this deep-shadow region. From this observation, together with the imediate onset of the effect synchroniously with the onset of ICRH, tro alternative conclusions may be drawn. Either, there occurs some direct energy transfer to the ions in this region, which is not caused by the energu losses from the heated toroidal tokamak olasma flowing into the scrapeoff layer: the energy decay length of about ! cm would be too short as compared to $6 \mathrm{~cm}$, the ion temperature would be too low for the measured sputtering yield and the onset of the sputtering signal would show a delay of the order $\tau_{\Sigma}$. Or alternatively, the observed sputtering may be caused by high energetic trapped ions with orbits extending into this region.

Fig. 16 shows the steep increase of the density profile in the scrape-off layer (limiter radius at $46 \mathrm{~cm}$ ) as a result of ICRH: this increase, however, is insufficient to explain the above mentioned $r$ ise of the (sputtered) iron density.

\section{Sawtooth Behavious during ICRH}

The observation made in TEXTOR concerning the sawtooth behaviour, can be sumarized as follows: 1) We observe all the variety of sawtooth behaviour already observed on other large tokamaks (e.g. /29/): single sawteeth, multiple sawteeth (up to 4 partial reccnnections), sawteeth with precursors or not, sawteeth with successors or not. 2) Sawteeth on both $T_{e o}$ and neo are contributing to the strong sawteeth on the central electron energy density $E_{\text {eo }}$ (see e.g. Fig. 10 of $/ 2 /$ ). The density sawteeth are mainly due to a density readjustment since the total number of particles $N_{e}$ (see F:g. 8b) is only sightly affected by sawtooth behaviour at the largest ICRH power levels achieved. 3) The sawooth period can be influenced by ICRH in different ways for roughly the same operating conditions and plasma Daraneters: two examples of the evolution of the period and of the aean slope dEeo/dt are given in Fig. 13a (same shot as Fig. 8) and Fig. 13b. At the beginning of the RF pulse the period continues its regular increase, already started in the of phase is. Fig. 13a, whereas the period decreases strongly in Fig. 13b. At the end of the ICRH pulse, as seen in $\bar{E}$ igs. $13 a$ and 13b, another regime of oscillation with compound sawteeth is often triggered. 4) The mean electron energy slope, during the sawtocth rise phase, decreases during the ICRH puise. The effect of this decrease on the sawtooth amplitude is partially compensated fo: by a simultaneous increase in the sawtooth period (see Figs. 8c and $13 b$ for t up to $1.4 \mathrm{~s}$ corresponding to the plasma current flat top). 5) The sawtooth period has been compared with the empirical scaling of McGuire and Robinson /30/. The result of this scaing is shoun by the dotted line in Fig. 13a. We take a as the characteristic length and $\tau_{\mathrm{H}}=\left(\mathrm{p}^{\prime} \mathrm{OH}^{+}\right.$ $\left.P_{R F, e}\right) /\left(3 / 2 n_{e o} T_{e o}\right)$ as heating time, where $P^{\prime} O H+P_{R F, e}$ is the cotal power density fed to the plasta. Agreement for the order of magnituce of the period is obtained but not for the detailed behaviour.

6) Large sawteeth are also observed on the neutron yielid anc thus cn the value of Iio derived from it. Fig. 14 a shows a case where the value of $T_{i o}$ jumps back to the equipartition value after each internal disruption. Another case showing oniy a s!ight sawtocth behavicur is given in Fig. 14b. No general rules for the occurrence (o: not) of large sawteeth have been deduced so far. 


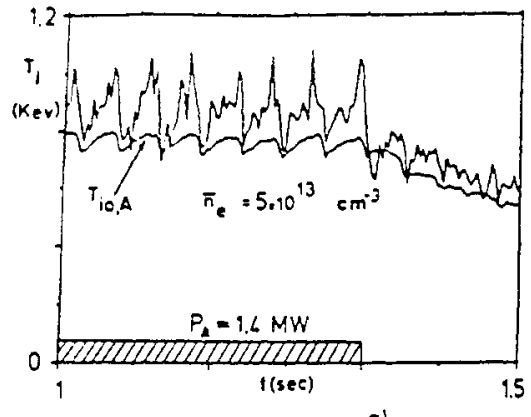

a)

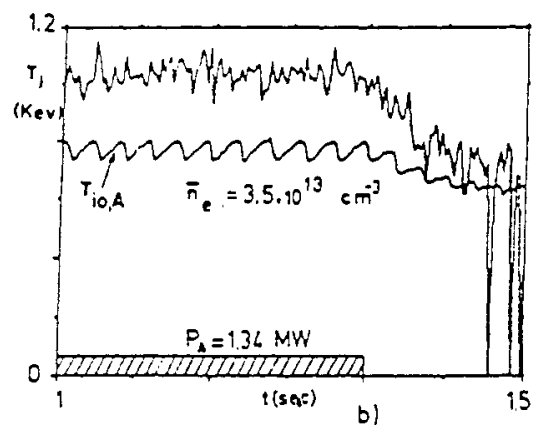

Fig. 15. Time evoilition of $T_{i o}$

measured from neutrons and computed from equipartition (T
for two different shots

(*18940, 18947).

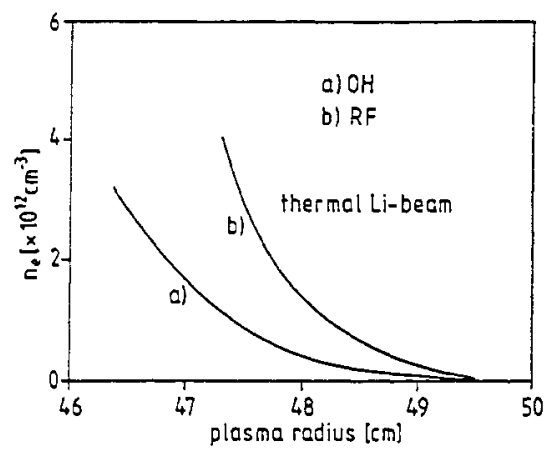

Fig. 16. Density profile in the scrape-off layer with ard without ICRH (Li-beam technique).
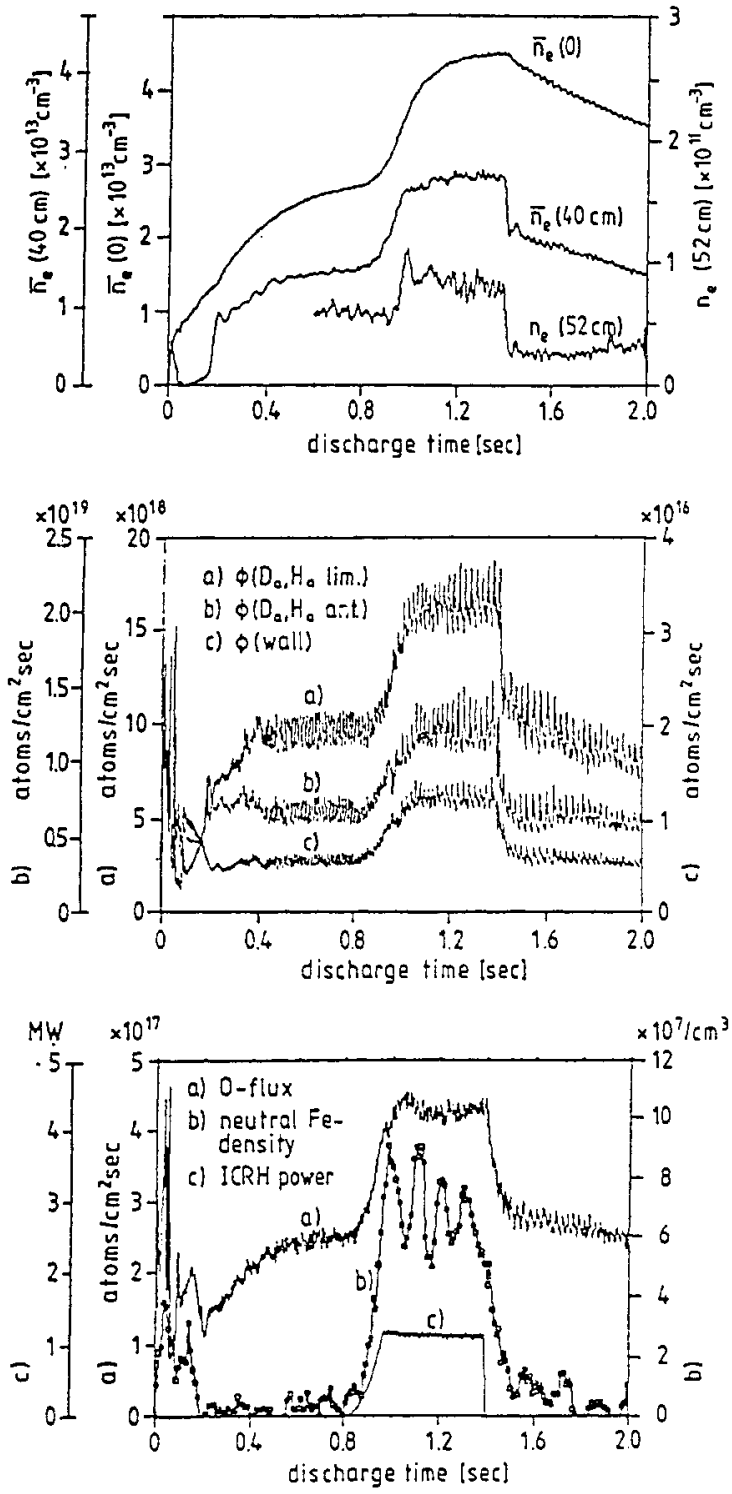

Fig. i5. Change of various $\bar{n}(r)$ ena flux signals as a response to $1.3 \mathrm{MH}$ ICKi. $\bar{n}(r)$ is the line averaged electron density along a chord with a distance $r$ off the center. 


\begin{tabular}{|l|l|l|}
\hline & $\begin{array}{l}\text { Previous Results } \\
X_{H} \cong 5-10 \%\end{array}$ & $\begin{array}{l}\text { Present Results } \\
x_{H}<1 \%\end{array}$ \\
\hline$\Delta T_{e O} / P_{R F}$ & $300 \mathrm{eV} / \mathrm{MW}$ & $160 \mathrm{eV} / \mathrm{MW}$ \\
$\Delta T_{i 0} / P_{\mathrm{RF}}$ & $180 \mathrm{eV} / \mathrm{MW}$ & $250 \mathrm{eV} / \mathrm{MW}$ \\
$\mathrm{n}_{e O}$ & $3.65 \times 10^{13} \mathrm{~cm}^{-3}$ & $3.95 \times 10^{13} \mathrm{~cm}^{-3}$ \\
$I_{\mathrm{p}}$ & $340 \mathrm{kA}$ & $480 \mathrm{kA}$ \\
\hline$P_{R F, e}$ & $150-170 \frac{\mathrm{mW}}{\mathrm{cm}^{3} \mathrm{MW}}$ & $50-60 \frac{\mathrm{mW}}{\mathrm{cm}^{3} \mathrm{MW}}$ \\
$P_{R F, i}$ & $60-95 \frac{\mathrm{mW}^{3}}{\mathrm{~cm}^{3} \mathrm{MW}}$ & $90-130 \frac{\mathrm{mW}}{\mathrm{cm}^{3} \mathrm{MW}}$ \\
\hline
\end{tabular}

TABLE 2 Observed central temperature increases and central power densities coupled to the elẻctrons and ions per MW applied ICRH in the present experiments (with low isotope rat io $X_{H}=N_{H} /\left(N_{H}+N_{D}\right)$ as compared with the previous mode conversion experinents

\section{SOME RESULTS OF THE PUMP LIMITER AND OF THE "ERGODIC LIMITER"}

One of the focal points of the TEXTOR experimental programe is the chatacterization of pump limiter capabilities for particle removal as an alternative to magnetic divertors. A schematic of the modular ALT-I (Advanced Limiter Test) pump limiter $/ 11,12,31,32 /$ is shown in Fig. I7 with one of the exchangeable limiter heads, the vacuun chamber $(V=7001)$ and the pumping system ( $S \leq 1.5 \times 10^{4} \mathrm{l} / \mathrm{s}$ ).

Maximum particle removal rates of $6 \times 10^{20}$ particles/s, corresponding to PxS about $10 \mathrm{Torr} 1 / \mathrm{s}$ ( $P$ : pressure, $S$ : pumping speed) were achieved, enough to allow an active density control. This can be made clear by the "effective" particle confinerent time $\tau_{p}^{*}$ which is the average lifetime of a particle before being either buried in the wall or putped away. In TEXTOR, pump limiter action reduces this time from typically 2-3 seconds to $1-1.5$ seconds. The removal efficiency PxS/Q $Q_{\text {n }}$ (Qn: particle fiux at the throat entrance) is found in the range of $0.5-1.0$. Assuming $\tau_{p}=\tau_{E}$, the estimated exhaust efficiency Pxs/(Ne/ $\left.\tau_{p}\right)$ :esults in values of up to $15 \%$. Please note, however, that the above mentioned gaximum values of pump limiter performance were achieved by using a graphite i imiter head covered with Tilcoating. The performance values of graphite limiter heads without such a coating were found to be typically a factor of 2 lower. This influence of aaterials on the performance may be explained by different radiation cooling layers leading to different electron temperature profiles in the boundary.

The removal efficiency can be affected by the electron temperature in the edge, with lower temperatures corresponding to higher removal rates. This observation is supported by Monte Carlo simulations of the neutral gas transport in the pump ismiter $/ 33$, $13 /$ winich for an electron temperature increasing from 5 to $30 \mathrm{eV}$ show a steep increase in the production rate for ion-electron pairs in the throat. In the calculations, this led to a significant attenuation of those neutrais which had a velocity component perpendicular to the dagnetic field lines, and which otherwise would be carried into the pumping duct.

Three different types of pump limiter heads have been used by now. They allowed to study the effect of different geometries concerning throat iengths and both open and closed configurations /12,31,32/. From these experiments results a guiding rule for pump limiter design: the 
effective pumping speed at the neutralizer plate, Seff, has to be large compared to the conductance $L$ for backstreaming of neutral gas from that region to the main plasma.

ALT-I has also been studied together with ICR heating. The power flux onto the limiter surface facing the plasma was found (infrared thermography) to increase at least as fast as the heating power $P$ transferred to the plasma. This is a further result indicating that the ICRH power is deposited, as desired, sufficiently beyond the scrape-off layer. On the other hand, these increased power fluxes in principle have the potential to seriously affect the design and the performance of pump limiters with respect to the required shape of the leading edge in view of the tolerable heat load. However, the increase of particle fluxes and of the resulting pressure in the ALT-I chamber, which has been observed simultaneously, alleviates the above mentioned difficulty. Higher fluxes and the corresponding degradation of particle confinement time $\tau_{p}$ are consistent with the observations uade at the main Iimiters mentioned earlier.

Experiments have been started to systematically evaluate the influence of the pump limiter on ICR heating ( $P>1.5 \mathrm{MW}$ ), especially on energy confinement and ICRH coupling. Preliminary results indicate no improvement, but also no degradation caused by ALT-I to ICR heated discharges; within the experimental ezror margins both, energy confinement tine and ICRH coupling remain unchanged.

\begin{abstract}
"Ergodic limiters" have been proposed /14,15,34,35/ as an instrument to further reduce the particle confinement in the boundary layer, in particular to achieve some cooling effect, to enhance the fluxes into the pump limiter, and, perhaps, to obtain some impurity shielding. In sumary, this method might help to approach the favourable regime of high local recycling in the boundary under non-divertor conditions.

For first experiments on this subject /16/, a localized multipolar perturbation coil has been applied on TEXTOR, acceoting the disadvantage of an increased manetic perturbation of the plasma core region as compared to large-area helical coil systems. When perturbation fields with a strength - averaged over the whole magnetic surface - of the order of $10^{-4}$ to $10^{-3}$ of the main field were applied, distinct helical structures of the boundary layer have been observed from the $D_{\alpha}$ exission there (Fig. 19). The observations confirm previous results /36/ and the explanation given there. These "optical islands" persisted also in cases where stronger perturbation fields have been applied (and a higher degree of "stochasticity" could have been expected).
\end{abstract}

Applying ergodization to pump imiter experiments, under certain conditions (isiand iocation or reduction in $\tau_{p}$ ) the particle flux into the pump limiter throat is significantly increased, whereas also reductions have been observed in orher cases.

Not only for the boundary layer but also for the core plasma rather intriguing but yet no clearcut results have been obtained at this early stage. Depending on discharge conditions in a rather subtle vay, both deterioration and improvement of core confinement and of YHD mode activity could be found. In particular, in some cases a pronounced m=2 MHD pode has been observed which rould be instantaneously hlocked by the onset of the external perturbation Eields (Fig. 20); alternatively. when the external verturbation fieid was ramped down, the develoment of such a mode has been observed.

The first experiments on the "ergodization" effects clearly demonstrated the potential of this conced to influence tokamak discharges in rany respects; further investigations are necessary to obtain a more systematic picture of the induced effects in order to learn better whether or how to profit from these capabilities.

\title{
ACKNOHLEDGEMENTS
}

The authors would like to acknowledge the helpful supdort of Dr. J. Eidens in preparing the manuscript and the continuous engagement of the TEXTOR operation team in providing, excellent experimental conoitions. 


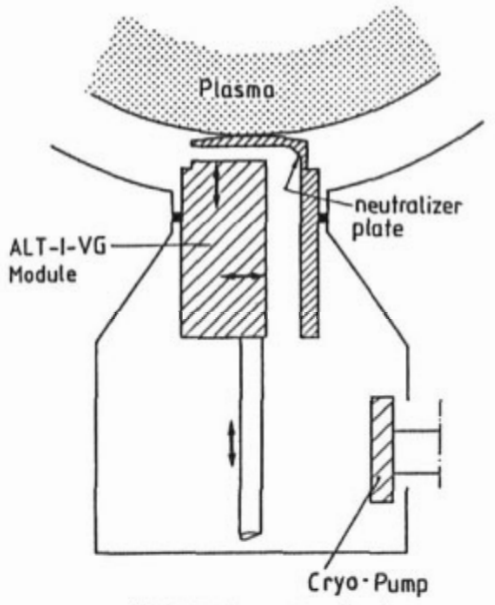

Variable Geometry Head

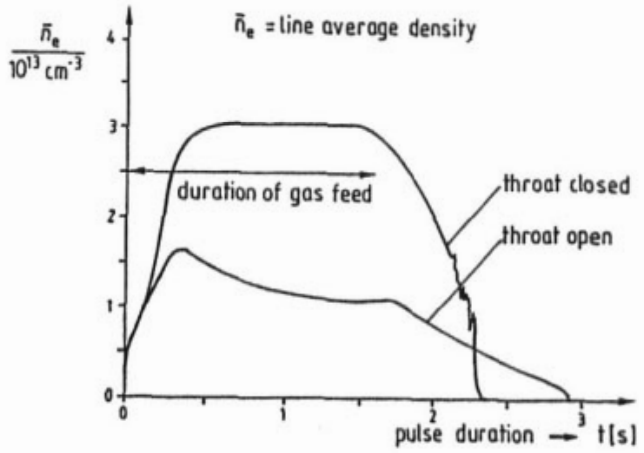

Fig. 18. Comparison of two discharges with identical gas feed, one with entrance throat closed (normal limiter operation), one with throat open (pump limiter mode).

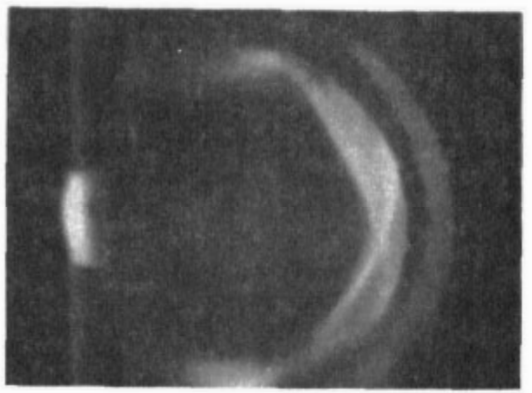

Fig. 19. Photograph in $D_{*}$ light (tangential view into the torus) of the island pattern caused by the external perturbation field.

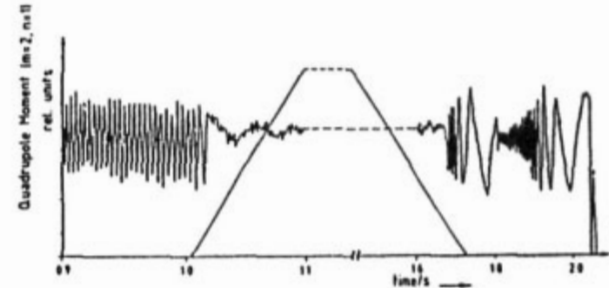

Fig. 20. Blocking of the otherwise persisting internal $m=2$ modes by the external perturbation field. 


\section{REFERENCES}

$1 /$ G.H. Wolf et al., J. Nucl. Mat. 122\&123, 1124 (1984)

$12 /$ F. Waelbroeck et al., JüL-1692 ( $\overline{1980}$ )

$13 /$ J. Winter et al., J. Nucl. Mat. 122\& 123, 1187 (1984)

14/ F. Waelbroeck et al., J. Nuc1.Mat. 121, 378 (1984)

15/ J. Winter, Proc. 7th Int. Conf. PSI, Princeton (May 1986)

16/ G. Fuchs, G. Waidmann et al., Proc. 13th Eur. Conf. Contr. Fusion and Plasma Heating, Schliersee (1986)

17/ A.M. Messiaen et al., Plasma Physics and Contr. Nucl. Fusion 28, 71 (1986)

/8/ R.R. Weynants et al., Proc. 13th Europ. Conf. Contr. Fus. and Plasma Heating, Schliersee (1986)

19/ B. Schweer et al., Proc. 13th Europ. Conf. Contr. Fus. and Plasma Heating, Schliersee (1986)

$110 /$ U. Sams et ai., 11th Synp. on Fusion Engineering, Austin/Tex. (Nov. 1985)

/ll/ W. Bieger et al., Proc. Int. Symp. on Plasma Wall Interaction, p. 609, Jïlich (1976), EUR 5782e Pergamon

$1 / 2 /$ A.E. Pontau et al., J. Nucl. Mat. $128 \& 129,434$ (1984)

/13/ D. Reiter et al., Proc. 13th Europ. Conf. Contr. Fus. and Plasma Heating, Schliersee (1985)

$114 /$ W. Feneberg, G.H. Wolf, Nuc1. Fus. 21, 669 (1981)

/15/ H. Belitz et al., Proc. Europ. Tok. Workshop XII/1238/82, p. 101, Schliersee (1982)

$/ 16 /$ G. Fuchs et al., Proc. 13th Europ. Conf. Contr. Fus. and Plasna Heating, Schliersee (1986)

/17/ H. Soltwisch et al., Aachen (1983), Plasma Phys. and Conte. Nucl. Fusion 26, $23(1984)$

$/ 18 /$ G. Waidmann et al., Nucl. Fus. Suppl., p. 193, IAEA Vienna (1985)

$/ 19 /$ H. Soltwisch, W. Stodiek, A. Kaleck, J. Schliter, Current Distribution and Magnetohydrodynamic Activity in TEXTOR Tokamak, APS Conference, San Diego (1985)

120/ H. Soltwisch, Current Distribution Measurement in a Tokamak by FIR Polarimetry, 6th APS Topical Conf. on High Temperature Diagnostics, Hilton Head, South Carolina, March 9-13, 1986 (to appear in Rev. Sci. Instr. 1986)

121/ See for instance J.A. Wesson, JET-P(85) 25 Report

/22/ W. Stodiek, private communication

/23/ R.R. Weynants et al., Radiofrequency Plasma Heating (Sixth Top. Conf., Calloway Gardens. GA. 1985) AIP Conference Proceedings, New York, No. 129, p. 40 (1985)

124/ R. Koch et al., Proc. 13th Europ. Conf. Contr. Fus. and Plasma Heating, Schliersee (1986)

/25/ W.D. Brüssau and H. Soltwisch, Real-Time Evaluation of Electron and Current Density Profile Parameters on TEXTOR, Jit-2016 (1985)

125/ S.M. Kaye and R.J. Goldston, Nucl. Fus. 25, 65 (1985)

127 F. Hagner et al., Proc. 12th Eur. Conf. on Controlled Fusion and Plasma Physics, Europhysics Conference Abstract, $9 F$ part 1, p. 335

$128 / \mathrm{J}$. Winter et al., Frühjahrstagung DPG Stuttgart (March 1986), Verhand1. DPG (vi) 21, 57

129/ K. McGuire et al., Proc. 12th Eur. Conf. on Controlled Fusion and Plasma Physics, Europhysics Conference Abstract, $9 \mathrm{~F}$ part 1, p. 134

130/ K. McGuire and D.C. Robinson, Nucl. Fus. 19, 505 (1979)

$131 /$ K.H. Dippel et al., Plasma Physics and Controlled Nuclear Fusion Research, I p. 249, IAEA Vienna (1985)

132/ K.H. Dippel et al., Proc. 12th Europ. Conf. Controlled Fusion and Plasma Physics, Budapest, p. 531 (1985)

133/ G.A. Campbell et al., UCLA-Rep. (1986), to be submitted to Ph. Rev. Let.

$134 / W$. Engelhardt, W. Feneberg, J. Nucl. Mat. $76 \& 77,518$ (1978)

/35/ A. Samain et al., J. Nucl. Mat. $128 \& 129,395$ (1984)

136/ N. Okyabu et a1., Nucl. Fus. 25, $1684 \overline{(1985)}$ 